\title{
Social determinants of pulmonary tuberculosis in Brazil: an ecological study
}

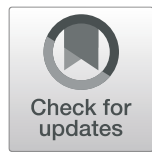

\author{
Alessandra Isabel Zille ${ }^{1,4^{*}}$ (D) Guilherme Loureiro Werneck ${ }^{2}$, Ronir Raggio Luiz ${ }^{2}$ and Marcus Barreto Conde ${ }^{1,3}$
}

\begin{abstract}
Background: Social determinants may influence the incidence and control of tuberculosis (TB). The aim of this study was to evaluate the correlation between social determinants and pulmonary TB (PTB) incidence and treatment outcomes in different regions in Brazil.
\end{abstract}

Methods: In this ecological study, PTB incidence and treatment outcome rates as well as HIV incidence for all 5560 Brazilian cities as reported to the Brazilian Tuberculosis Program in 2010 were correlated with two social indicators, the Human Development Index (HDI) and Gini Index (Gl). Cities were stratified into six groups based on location (metropolitan region or not) and size (small, medium, and large cities), and according to the regions of the country to which they belong. The Spearman correlation coefficient was used to assess the association between variables.

Results: In 2010, 68,729 new PTB cases were reported in Brazil, with an incidence rate of 36 cases per 100,000 inhabitants. Incidence rates and PTB mortality demonstrated a weak negative correlation with HDI and a positive correlation with Gl. The correlation between $\mathrm{HDI}$ and $\mathrm{Gl}$ with cure, relapse, and lost to follow-up of treatment greatly varied in the different groups of cities and regions of the country evaluated.

Conclusions: There is a weak correlation between HDI and GI and PTB incidence and mortality rate. However, there is great variation between the $\mathrm{HDI}$ and $\mathrm{Gl}$ and cure, relapse, and lost to follow-up in the different groups of cities and regions of the country. This suggests that for TB determination, these outcome variables might be more related to the quality of healthcare provided by services than to social determinants in the general population.

Keywords: Tuberculosis, Income, Inequality, Social indicators

\section{Background}

Brazil is a member of BRICS (Brazil, Russian Federation, India, China, and South Africa), a group of countries that together represent approximately $50 \%$ of tuberculosis (TB) cases worldwide [1]. However, since the 1980s, the incidence rate of pulmonary TB (PTB) in Brazil has decreased, which ranged from 70.4 TB cases/ 100,000 inhabitants in 1982 to $32.4 / 100,000$ in 2016 [2,3]. Surprisingly, the decrease in the TB incidence rate has not been followed by an improvement in other data related to TB control such as treatment outcomes. In fact, throughout this period, cure rates remained low (approximately 65\%),

\footnotetext{
* Correspondence: alezille@uol.com.br

1 Instituto de Doenças do Tórax da Universidade Federal do Rio de Janeiro, Rio de Janeiro, RJ, Brazil

${ }^{4}$ Hospital Universitário Clementino Fraga Filho, Cidade Universitária, Rua, Professor Rodolpho Paulo Rocco n² 255, $6^{\circ}$ andar, Rio de Janeiro 21941-913, Brazil

Full list of author information is available at the end of the article
}

while lost to follow-up and TB mortality persisted at high levels (approximately 13 and 7\%, respectively). Moreover, the increase in the number of multi drug resistance tuberculosis (MDR TB) cases has been well documented [4]. In addition, data from a recent study suggest that despite the changes implemented by the Brazilian TB National Program in 2009 (adding ethambutol to the therapeutic regimen and adopting fixed-dose combined pills, inter alia), these rates are deteriorating [5]. One possible reason for the reduction in the $\mathrm{TB}$ incidence rate in a setting where other indices of TB control are deteriorating might be improved social and quality of life factors. In fact, while the PTB incidence rate is less than 10 cases per 100,000 inhabitants per year in high-income countries including those in Europe, Canada, the United States, Japan, Australia, and New Zealand, low-income countries such as Mozambique, South Africa, and Zimbabwe present rates above 500/100,000 inhabitants [6]. Data also 
demonstrate an inverse relationship between TB incidence and Gross Domestic Product (GDP) [7]. An ecological study in 2000 in California demonstrated that a higher per capita income might act as a "protector" factor for communicable diseases like TB [8]. According to Ploubidis (2012), income inequality is a significant predictor of country-level variation in TB rates, with less inequality associated with a lower TB incidence rate and prevalence [9].

Brazil experienced a significant increase in GDP per capita after the stabilization of the economy in the 1990s. The country has also implemented different social policies in recent years to partially reduce absolute poverty and income inequality [10]. However, Brazil is a continental country and still has significant socioeconomic disparity, with a broad variation of GDP and inequality of income distribution among its different regions [11, 12]. A study conducted in Brazil (1998-2006) associated higher TB/HIV incidence rates and areas with lower socioeconomic levels in the city of São Paulo [13]. Another study conducted between 1990 and 2010 among HIV positive and negative TB patients suggested a correlation between the TB/HIV coinfection rate and poverty in Brazil [14]. Furthermore, an ecological cohort conducted between 2000 and 2005 in the city of Porto Alegre demonstrated from the spatial perspective that the mean annual incidence of $\mathrm{TB}$ is not homogenously distributed along the city's territory. Similarly, the non-spatial analysis demonstrated the narrow relation between $\mathrm{TB}$ and social determinants, concentrating the highest rates in the lower socioeconomic districts [15]. To our knowledge, no national study to date has evaluated the association between social determinants and TB indices in all Brazilian cities. While existing studies clarify the association between social inequality and the incidence of $\mathrm{TB}$, there is no correlation between social determinants and the main treatment outcomes (lost to follow-up, relapse, cure, mortality). As such, this paper reports a comparative study between social chains and TB incidence rate, cure, lost to follow-up, recurrence, and mortality in Brazil, considering 5560 municipalities in total and separately to evaluate the influence of the heterogeneity of the population groups evaluated.

\section{Methods}

Study design

Ecological study

Studied variables The study was conducted using all 5560 Brazilian cities that existed in 2010 as the unit of analysis. We evaluated all new pulmonary TB (РTB) cases, treatment outcomes (lost to follow-up, cure, mortality), and relapse rates reported to the Brazilian Diseases Information System (SINAN) by city of residence. Extrapulmonary TB cases were excluded from the analysis based on the lack of evidence of its association with social determinants. We used the TB definition as revised by the WHO in 2013 [16]. The proportion of cure, relapses, and lost to follow-up cases among the total number of PTB cases were evaluated for each city in 2010 [17, 18]. Death due to PTB was assessed according to the International Classification of Diseases (ICD A15-A16). Direct standardization by age group was performed in the calculation of mortality rates by city. The standard population was that of the 2010 Brazilian Census [12, 19].

For social determinants, we evaluated the Human Development Index (HDI) and Gini Index (GI). GI is a globally used indicator that enables analyzing the socioeconomic situation of the population, identifying segments that require greater attention from public health policies, as well as education and social protection, among other factors [20, 21]. It measures the degree of income concentration in a particular group, indicating the differences between the incomes of the poorest and richest. Reportedly, the HDI is one determinant closely correlated with $\mathrm{TB}$ incidence by the Commission on Social Determinants of Health (CSDH), forming part of the structural determinants of health that generate or reinforce social stratification [22, 23]. HDI uses an arithmetic average of indices related to three dimensions of human development: longevity, education, and income. Numerically, both indices vary from zero to one and have inverse meanings. For the GI, a zero value represents the situation of equality of income distribution, meaning that everyone has the same income. A value near to one means that a few people hold all the wealth [24]. HDI also varies from zero to one. However, the closer to one the value, the higher is the human development [23]. Since the HDI and GI indices are not published annually for each city, this study used the most recent year (2010) for which both indices and official TB data were reported in Brazil.

Because HIV infection might be a confounding variable in the association between $\mathrm{TB}$ and social determinants, we also used the HIV rate as a predictor variable. Because the testing rate among TB cases in Brazil is low, we used the HIV rate reported to the Brazilian AIDS Program in each municipality.

Characteristics of the population Brazil is a large country with a heterogeneous population distributed across 5560 cities living in different social and geographical conditions. Therefore, clusters based on characteristics such as geographic distribution (macro-regions), number of inhabitants, rural or metropolitan location, and population density were used to evaluate the correlation between the HDI and GI with TB. Cities were stratified into six groups: small, medium, and large cities, 
belonging or not to a metropolitan area. Small cities were considered those with fewer than 50,000 people and a population density of less than 80 inhabitants/ $\mathrm{km}^{2}$. Medium cities were those with populations between 50,000 and 100,000 inhabitants or with a population density above 80 inhabitants $/ \mathrm{km}^{2}$ (predominating the number of inhabitants in the classification), while large cities were those with a population of more than 100,000 inhabitants, regardless of population density [25]. A metropolitan region was considered a cluster of neighboring municipalities established by law for the planning and execution of public functions of common interest, often featuring a large urbanized region formed by the city core and adjacent cities [12]. The five macro-regions in Brazil are the North (seven states), Northeast (nine states), Southeast (four states), South (three states), and Midwest (three states). The municipalities were also grouped according to the region to which they belong based on the five macro-regions of Brazil: North (seven states), Northeast (nine states), Southeast (four states), South (three states), and Midwest (three states).

Statistical analysis The mean and total number of cases were used for descriptive purposes. The Spearman correlation coefficient $\left(r_{s}\right)$ was used as the measure of association to determine the strength of the relationship between variables, which varies from -1 (perfect negative correlation) to +1 (perfect positive correlation). A value of $r_{s}=0$ means no correlation between variables. The closer the extreme value of $r_{s}(-1$ or +1$)$, the greater is the association between variables. The size of the correlation of values different from 1 was interpreted as follows: $\leq 0.30$ as a negligible correlation, 0.30 to 0.50 as low, 0.50 to 0.70 as moderate, and from 0.70 to 0.90 as a high positive correlation [26]. Statistical analyses were processed using the Statistical Package for Social Sciences (SPSS) version 22.0 for Windows software.

Data sources The data used in this study were collected from different information systems according to the variable studied (updated October 2014). Data on PTB new cases, cure, relapse, and lost to follow-up of the treatment were collected from SINAN. Data on PTB mortality were extracted from the Brazilian Mortality Information System (Sistema de Informação de Mortalidade, SIM). The number of AIDS cases, GI, and population of each city used to calculate the PTB incidence rates and mortality (data from the 2010 Brazilian Census) were obtained from the Department of Statistics of the Unified Health System (DATASUS). The United Nations Program for Development (UNDP) served as the source for the HDI for each city.
Ethical approval The study was submitted to the Institutional Review Board (IRB) of the Federal University of Rio de Janeiro with the number 281.382 and was approved on May 9, 2013 without further analysis, because it was an ecological study based on public secondary data. The data used for this study are public and can be accessed freely on the electronic addresses of the Brazilian Government [2-4].

\section{Results \\ General data}

In 2010, Brazil housed 190,731,964 inhabitants in 5560 cities. The heterogeneity in population distribution is presented in Table 1. It is evident that $41 \%(78,483,169 /$ $190,731,964$ inhabitants) of the country's population was concentrated in 154 large metropolitan cities. In $31.2 \%$ $(1733 / 5560)$ of the cities, no new PTB cases were reported in 2010, and of these, $88.1 \%$ were small cities not located in a metropolitan area $(1528 / 1733)$ (Table 1$)$.

In 2010, 71,919 PTB cases were reported in Brazil, of which $95.6 \%(68,729 / 71,919)$ were new cases corresponding to an incidence rate of 36 per 100,000 inhabitants. The proportion of those cured was $69 \%(49,585 /$ $71,919)$, of relapse $7 \%(4827 / 71,919)$, of lost to follow-up $12 \%(9052 / 71,919)$, and of deaths due to PTB 6\% (4235/ $71,919)$. The average standardized mortality rate in 2010 was 1.5 per 100,000 inhabitants. In total, 37,331 new AIDS cases were reported in the general population, corresponding to an incidence rate of 19.5 per 100,000 inhabitants (Table 1). In Brazil (2010), the HDI average was 0.65 and GI 0.50 .

Table 2 shows that the largest number of new PTB cases occurred in the Southeast region (30,863 PTB new cases), but the highest average incidence rate was in the Southern region $(26.9$ cases/100,000). The highest average cure proportion was in the Northern region (85.5\%). The highest average lost to follow-up proportion was in the Northeast region (5.7), and the lowest in the South (4.2).

There was a higher proportion of relapse in the Northeast region (5.1/100,000). The highest rates of AIDS incidence were in the South $(11.3 / 100,000)$ and Southeast $(10.3 / 100,000)$, while the highest rate of PTB mortality was in the Northeast region $(1.9 / 100,000)$ (Table 2).

\section{Correlation between variables}

Table 3 shows that the PTB incidence rate is negatively correlated with HDI (meaning an inverse association between these two variables: the higher the HDI, the lower the TB incidence rate) in all groups of cities. The correlation was not statistically significant in medium cities (metropolitan and non-metropolitan) or small cities located in a metropolitan area. In addition, the correlation was negligible $(\leq 0.30)$ in all groups except in 
Table 1 Pulmonary tuberculosis and AIDS data and the HDI and GI in different groups of cities in Brazil

\begin{tabular}{|c|c|c|c|c|c|c|c|c|c|c|c|c|c|c|}
\hline \multirow{5}{*}{$\begin{array}{l}\text { Variable } \\
\text { Population group }\end{array}$} & \multirow{3}{*}{\multicolumn{2}{|c|}{$\begin{array}{l}\text { Country } \\
\text { Brazil }\end{array}$}} & \multicolumn{12}{|c|}{ Groups of cities } \\
\hline & & & \multicolumn{6}{|c|}{ Metropolitan area } & \multicolumn{6}{|c|}{ No metropolitan area } \\
\hline & & & \multicolumn{2}{|l|}{ Small } & \multicolumn{2}{|c|}{ Medium } & \multicolumn{2}{|l|}{ Large } & \multicolumn{2}{|l|}{ Small } & \multicolumn{2}{|c|}{ Medium } & \multicolumn{2}{|c|}{ Large } \\
\hline & $\left.\overline{\mathrm{HDl}}\right|^{\mathrm{a}}$ & $\mathrm{Gl}^{\mathrm{a}}$ & $\overline{\mathrm{HDI}} \mathrm{I}^{\mathrm{a}}$ & $\mathrm{Gl}^{\mathrm{a}}$ & $\left.\overline{\mathrm{HDl}}\right|^{\mathrm{a}}$ & $\mathrm{Gl}^{a}$ & $\overline{\mathrm{HDI}}{ }^{a}$ & $\mathrm{Gl}^{a}$ & $\overline{\mathrm{HDI}} \mathrm{I}^{\mathrm{a}}$ & $\mathrm{Gl}^{\mathrm{a}}$ & $\overline{\mathrm{HDl}} \mathrm{a}^{\mathrm{a}}$ & $\mathrm{Gl}^{\mathrm{a}}$ & $\overline{\mathrm{HDl}^{\mathrm{a}}}$ & $G l^{a}$ \\
\hline & 0.65 & 0.50 & 0.67 & 0.47 & 0.69 & 0.48 & 0.74 & 0.51 & 0.64 & 0.50 & 0.66 & 0.51 & 0.73 & 0.53 \\
\hline Inhabitants & \multicolumn{2}{|c|}{$190,731,964$} & \multicolumn{2}{|c|}{$3,998,698$} & \multicolumn{2}{|c|}{$8,783,630$} & \multicolumn{2}{|c|}{$78,483,169$} & \multicolumn{2}{|c|}{$48,579,389$} & \multicolumn{2}{|c|}{$24,634,920$} & \multicolumn{2}{|c|}{$26,252,158$} \\
\hline PTB new cases $(\mathrm{N})$ & \multicolumn{2}{|c|}{68,729} & \multicolumn{2}{|l|}{851} & \multicolumn{2}{|c|}{3316} & \multicolumn{2}{|c|}{40,801} & \multicolumn{2}{|c|}{10,113} & \multicolumn{2}{|l|}{6271} & \multicolumn{2}{|l|}{7377} \\
\hline PTB incidence rate & \multicolumn{2}{|l|}{36} & \multicolumn{2}{|l|}{21.2} & \multicolumn{2}{|l|}{37.7} & \multicolumn{2}{|l|}{51.9} & \multicolumn{2}{|l|}{20.8} & \multicolumn{2}{|l|}{25.4} & \multicolumn{2}{|l|}{28.1} \\
\hline Cities with no new PTB case(s) & 1733 & & 134 & & 17 & & 1 & & 1528 & & 53 & & 0 & \\
\hline Cure (total n of cases) & 49,58 & & 635 & & 2442 & & 28,331 & & 7760 & & 4743 & & 5674 & \\
\hline Cure (\%) & 69 & & 43.3 & & 64.7 & & 72 & & 45.8 & & 65.2 & & 74.7 & \\
\hline Lost to follow-up (N) & 9052 & & 79 & & 360 & & 6492 & & 748 & & 607 & & 766 & \\
\hline Lost to follow-up (\%) & 12 & & 4.1 & & 8.9 & & 11.8 & & 4.2 & & 7.4 & & 9.2 & \\
\hline Relapse (N) & 4827 & & 65 & & 287 & & 2925 & & 704 & & 437 & & 409 & \\
\hline Relapse (\%) & 7 & & 4.3 & & 6.7 & & 6.5 & & 4 & & 6.2 & & 5.4 & \\
\hline $\operatorname{AIDS}(\mathrm{N})$ & 37,33 & & 460 & & 1702 & & 22,782 & & 3723 & & 3215 & & 5449 & \\
\hline AIDS incidence rate & 19.5 & & 11.5 & & 19.3 & & 29 & & 7.6 & & 13 & & 20.7 & \\
\hline Death due to PTB (N) & 4235 & & 45 & & 186 & & 2402 & & 757 & & 412 & & 433 & \\
\hline Death due to PTB Incidence rate ${ }^{b}$ & 1.5 & & 0.91 & & 2.28 & & 3.68 & & 1.4 & & 1.66 & & 1.78 & \\
\hline
\end{tabular}

Incidence rates per 100,000 population

Small Cities $<50,000$ inhabitants and density $<80$ inhabitants $/ \mathrm{km}^{2}$, medium cities population between 50,000 and 100,000 or density $>80$ inhabitants/km ${ }^{2}$, large cities population $>100,000$ inhabitants. The variables cure, relapse, and lost to follow-up are provided as an average of percentages in the groups of cities AIDS Acquired Immunodeficiency Syndrome, HDI Human Development Index, GI Gini Index

${ }^{\mathrm{a}}$ The $\mathrm{HDI}$ and $\mathrm{Gl}$ show the average by population group. ${ }^{\mathrm{b}}$ Mortality rate due to PTBwas calculated by direct standardization

Table 2 Pulmonary tuberculosis and AIDS data and the HDI and Gl in five macro-regions of Brazil

\begin{tabular}{|c|c|c|c|c|c|c|c|c|c|c|}
\hline \multirow[t]{5}{*}{ Variable } & \multicolumn{10}{|c|}{ Brazilian regions } \\
\hline & \multicolumn{2}{|c|}{ North } & \multicolumn{2}{|c|}{ Northeast } & \multicolumn{2}{|c|}{ Southeast } & \multicolumn{2}{|c|}{ South } & \multicolumn{2}{|c|}{ Midwest } \\
\hline & \multicolumn{2}{|c|}{449 cities } & \multicolumn{2}{|c|}{1792 cities } & \multicolumn{2}{|c|}{1668 cities } & \multicolumn{2}{|c|}{1188 cities } & \multicolumn{2}{|c|}{463 cities } \\
\hline & $\mathrm{HDI}$ & $\mathrm{Gl}$ & $\mathrm{HDI}$ & $\mathrm{Gl}$ & $\mathrm{HDI}$ & Gl & $\mathrm{HDI}$ & Gl & $\mathrm{HDI}$ & $\mathrm{Gl}$ \\
\hline & 0.60 & 0.57 & 0.59 & 0.53 & 0.69 & 0.47 & 0.71 & 0.46 & 0.68 & 0,50 \\
\hline Inhabitants & \multicolumn{2}{|c|}{$15,864,454$} & \multicolumn{2}{|c|}{$53,071,442$} & \multicolumn{2}{|c|}{$80,364,410$} & \multicolumn{2}{|c|}{$27,386,891$} & \multicolumn{2}{|c|}{$14,044,767$} \\
\hline PTB cases $(N)$ & \multicolumn{2}{|l|}{7167} & \multicolumn{2}{|c|}{20,889} & \multicolumn{2}{|c|}{31,733} & \multicolumn{2}{|l|}{8979} & \multicolumn{2}{|c|}{3151} \\
\hline PTB new cases $(\mathrm{N})$ & \multicolumn{2}{|l|}{6791} & \multicolumn{2}{|c|}{19,623} & \multicolumn{2}{|c|}{30,863} & \multicolumn{2}{|l|}{8459} & \multicolumn{2}{|c|}{2993} \\
\hline PTB incidence rate & \multicolumn{2}{|l|}{23.7} & \multicolumn{2}{|l|}{21.9} & \multicolumn{2}{|l|}{21.9} & \multicolumn{2}{|l|}{26.9} & \multicolumn{2}{|l|}{18.2} \\
\hline Cities with no new PTB cases & \multicolumn{2}{|l|}{106} & \multicolumn{2}{|l|}{380} & 542 & & 535 & & 170 & \\
\hline Cure (total n of cases) & 5234 & & 13,925 & & 22,219 & & 6089 & & 2118 & \\
\hline Cure(\%) & 85.5 & & 55.3 & & 50.7 & & 40.6 & & 44.5 & \\
\hline Lost to follow-up (N) & 798 & & 2516 & & 4240 & & 1169 & & 329 & \\
\hline Lost to follow-up(\%) & 11.7 & & 12.8 & & 13.7 & & 13.8 & & 10.9 & \\
\hline Relapse (N) & 339 & & 1385 & & 2145 & & 791 & & 167 & \\
\hline Relapse (\%) & 2.9 & & 5.1 & & 4.3 & & 4.7 & & 3.2 & \\
\hline AIDS incidence rate & 8.8 & & 6.2 & & 10.3 & & 11.3 & & 9.5 & \\
\hline Death due to PTB rate $(\mathrm{N})$ & 330 & & 1247 & & 1171 & & 1133 & & 354 & \\
\hline Death due to PTB rate & 1.5 & & 1.9 & & 1.5 & & 0.9 & & 1.8 & \\
\hline
\end{tabular}

Mortality rate due to PTBwas calculated by direct standardization. Incidence rates per 100,000 population. The variables cure, relapse, and lost to follow-up are given as an average of percentages in the regions 
Table 3 Correlation coefficients between rates related to PTB and HDI/GI in cities classified by size and population aggregation

\begin{tabular}{|c|c|c|c|c|c|c|c|c|c|c|c|c|c|c|}
\hline \multirow{4}{*}{$\begin{array}{l}\text { Variable } \\
\text { Population group }\end{array}$} & \multicolumn{2}{|c|}{ Country } & \multicolumn{12}{|c|}{ Groups of cities } \\
\hline & & & \multicolumn{6}{|c|}{ Metropolitan area } & \multicolumn{6}{|c|}{ No metropolitan area } \\
\hline & \multicolumn{2}{|l|}{ Brazil } & \multicolumn{2}{|l|}{ Small } & \multicolumn{2}{|c|}{ Medium } & \multicolumn{2}{|l|}{ Large } & \multicolumn{2}{|l|}{ Small } & \multicolumn{2}{|c|}{ Medium } & \multicolumn{2}{|l|}{ Large } \\
\hline & $\mathrm{HDI}$ & $\mathrm{Gl}$ & $\mathrm{HDI}$ & $\mathrm{Gl}$ & $\mathrm{HDI}$ & $\mathrm{Gl}$ & $\mathrm{HDI}$ & $\mathrm{Gl}$ & $\mathrm{HDI}$ & $\mathrm{Gl}$ & $\mathrm{HDI}$ & $\mathrm{Gl}$ & $\mathrm{HDI}$ & Gl \\
\hline PTB new cases & $-0.05^{b}$ & $0.18^{b}$ & -0.01 & $0.15^{b}$ & -0.07 & $0.16^{a}$ & $-0.25^{b}$ & 0.13 & $-0.16^{b}$ & $0.17^{b}$ & -0.03 & $0.15^{\mathrm{b}}$ & $-0.42^{b}$ & $0.44^{b}$ \\
\hline Cure & -0.02 & $0.13^{b}$ & 0.05 & 0.04 & $0.17^{\mathrm{a}}$ & -0.04 & $0.28^{\mathrm{b}}$ & -0.09 & $-0.11^{b}$ & $0.16^{\mathrm{b}}$ & $0.11^{\mathrm{b}}$ & -0.03 & 0.06 & -0.05 \\
\hline Lost to follow-up & $0.09^{b}$ & $0.14^{\mathrm{b}}$ & -0.03 & $0.17^{\mathrm{b}}$ & -0.01 & -0.02 & -0.13 & 0.18 & $-0.07^{\mathrm{b}}$ & $0.12^{\mathrm{b}}$ & 0.08 & $0.12^{\mathrm{b}}$ & 0.13 & -0.01 \\
\hline Relapse & $0.1^{b}$ & $0.11^{\mathrm{b}}$ & -0.02 & $0.13^{\mathrm{a}}$ & 0.11 & 0.09 & 0.09 & -0.08 & $-0.06^{b}$ & $0.09^{b}$ & $0.14^{\mathrm{b}}$ & 0.05 & -0.02 & -0.2 \\
\hline AIDS & $0.27^{\mathrm{b}}$ & $0.03^{\mathrm{a}}$ & $0.1^{\mathrm{a}}$ & 0.04 & $0.37^{b}$ & $-0.22^{\mathrm{a}}$ & $0.18^{\mathrm{a}}$ & 0.07 & $0.14^{\mathrm{b}}$ & $0.04^{b}$ & $0.34^{\mathrm{b}}$ & -0.07 & $0.26^{\mathrm{b}}$ & 0.04 \\
\hline Death due to PTB & $0.02^{\mathrm{a}}$ & $0.16^{\mathrm{b}}$ & -0.08 & $0.14^{\mathrm{a}}$ & $-0.14^{\mathrm{a}}$ & $0.22^{\mathrm{b}}$ & $-0.44^{b}$ & 0.06 & $-0.11^{b}$ & $0.14^{\mathrm{b}}$ & -0.01 & $0.18^{\mathrm{b}}$ & $-0.35^{b}$ & $0.34^{\mathrm{b}}$ \\
\hline
\end{tabular}

Brazilian population in 2010: 190,731,964 inhabitants. Incidence rate per 100,000population. Small Cities< 50,000inhabitantsand density < 80 inhabitants/km², medium cities population between 50,000 and 100,000 or density $>80$ inhabitants $/ \mathrm{km}^{2}$, large cities population $>100,000$ inhabitants

Coefficients were calculated between the HDI/GI and \% of cure, \% lost to follow-up, \% relapse, PTB incidence rate, AIDS incidence rate, and rate of deaths due to PTB (calculated by direct standardization)

AIDS Acquired Immunodeficiency Syndrome, HDI Human Development Index, GI Gini Index

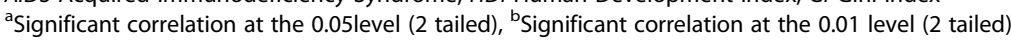

large/non-metropolitan groups of cities $\left(r_{s}=-0.42\right)$. PTB incidence rates correlated positively with the GI in all groups (meaning a direct association between these two variables: the higher the GI, the higher the TB incidence rate), and the correlation was statistically significant in all groups, except large cities located in a metropolitan area. Again, the correlation was negligible $(\leq 0.30)$ in all groups except in large/non-metropolitan groups of cities $\left(r_{s}=0.44\right)$.

The cure rate was positively associated with HDI in most groups (the higher the HDI, the higher the cure rate), except in small non-metropolitan cities. However, the correlation was negligible in all groups and statistically significant in just two groups (Table 3). The correlation between the GI and cure rate did not present a single pattern, and was positive (the higher the inequality, the higher the cure rate) in three groups and negative (the lower the GI or inequality, the higher the cure rate) in four groups. In all groups, the correlation between the GI and cure rate was negligible $(\leq 0.30)$.

Lost to follow-up and HDI were positively correlated (the higher the HDI, the higher the lost to follow-up) in four groups and negatively correlated (the higher the HDI, the lower the lost to follow-up) in three groups (Table 3). Lost to follow-up and the GI were positively correlated (the higher the GI or inequality, the higher the lost to follow-up) in five groups (in which four were statistically significant) and negatively correlated (the higher the GI or inequality, the lower the lost to follow-up) in two groups (Table 3). However, in all groups, the correlation between the HDI and GI with lost to follow-up was negligible $(\leq 0.30)$.

Relapse and HDI correlated (negligibly) with a mixed pattern, and the correlation was significant and positive in non-metropolitan medium cities $\left(r_{s}=0.14\right)$ and negative in small and non-metropolitan cities $\left(r_{s}=-0.06\right)$
(Table 3). The correlation between the GI and relapse was positive in all five regions and in all cities except large ones (metropolitan and non-metropolitan).

Death and HDI were negatively correlated (negligibly) in all groups of cities (Table 3) and positively correlated (Table 4) in five regions of Brazil. The correlation between the GI and death was positive in all cities and all five regions. Table 3 also shows a positive and significant correlation between the AIDS incidence rate and HDI in all groups. It was more evident in medium cities (metropolitan and non-metropolitan) and agreed with the national correlation, which was also positive $\left(r_{s}=0.27\right)$.

Table 4 shows a negative correlation between HDI for the majority of variables studied (incidence, cure, lost to follow-up, and relapse) in the North region (the higher the HDI, the lower the rate of the variable evaluated). It also demonstrated a positive correlation between the HDI for most variables (the higher the HDI, the higher the rate of the variable evaluated) in the remaining four regions (Northeast, Southeast, South, and Midwest). The correlation between the GI and all variables studied was positive (the higher the GI or inequality, the higher the rate of the variable evaluated) in all five regions with only one exception (Table 4). Again, with few exceptions, the correlation between the HDI and GI with incidence rate, cure, lost to follow-up, relapse, AIDS, and death due to TB was negligible $(\leq 0.30)$ in all regions evaluated.

\section{Discussion}

To our knowledge, this is the first study to evaluate the association between the HDI and GI with the incidence rates of $\mathrm{PTB}$, cure rate, lost to follow-up, recurrence, and death due to TB, as well as AIDS in Brazil city by city according to different population groups and regions of the country (including all 5560 cities). Our data weakly correlated the HDI and GI with the incidence 
Table 4 Correlation coefficients between rates related to PTB and the HDI/GI in Brazil'sfive macro-regions

\begin{tabular}{|c|c|c|c|c|c|c|c|c|c|c|}
\hline \multirow[t]{4}{*}{ Variable } & \multicolumn{10}{|c|}{ Brazilian regions } \\
\hline & \multicolumn{2}{|l|}{ North } & \multicolumn{2}{|c|}{ Northeast } & \multicolumn{2}{|c|}{ Southeast } & \multicolumn{2}{|c|}{ South } & \multicolumn{2}{|c|}{ Midwest } \\
\hline & \multicolumn{2}{|c|}{449 cities } & \multicolumn{2}{|c|}{1792 cities } & \multicolumn{2}{|c|}{1668 cities } & \multicolumn{2}{|c|}{1188 cities } & \multicolumn{2}{|c|}{463 cities } \\
\hline & $\mathrm{HDI}$ & $\mathrm{Gl}$ & $\mathrm{HDI}$ & $\mathrm{Gl}$ & $\mathrm{HDI}$ & $\mathrm{Gl}$ & $\mathrm{HDI}$ & $\mathrm{Gl}$ & $\mathrm{HDI}$ & $\mathrm{Gl}$ \\
\hline Incidence rate of TB & -0.11 & 0.22 & 0.18 & 0.08 & 0.13 & 0.15 & 0.05 & 0.44 & -0.02 & 0.25 \\
\hline Cure & -0.14 & 0.2 & 0.07 & 0.06 & 0.14 & 0.12 & 0.05 & 0.03 & 0.04 & 0.24 \\
\hline Lost to follow-up & -0.01 & 0.09 & 0.20 & 0.08 & 0.30 & 0.21 & 0.14 & 0.05 & 0.14 & 0.15 \\
\hline Relapse & -0.05 & 0.01 & 0.24 & 0.08 & 0.27 & 0.18 & 0.15 & 0.68 & 0.15 & 0.2 \\
\hline AIDS & 0.2 & -0.02 & 0.27 & 0.09 & 0.38 & 0.1 & 0.23 & 0.1 & 0.17 & 0.1 \\
\hline Death dueto PTB & 0.07 & 0.01 & 0.16 & 0.09 & 0.23 & 0.2 & 0.11 & 0.11 & 0.1 & 0.21 \\
\hline
\end{tabular}

Death due to PTB rate calculated by direct standardization. Incidence rates per 100,000 population. Coefficients were calculated between the HDI/GI and \% of cure, \% lost to follow-up, \% relapse, PTB incidence rate, death due to PTB rate, and AIDS incidence rate AIDS Acquired Immunodeficiency Syndrome, HDI Human Development Index, GI Gini Index

and mortality rate of $\mathrm{PTB}$, and demonstrated great variation between the HDI and GI and the cure, relapse, and lost to follow-up in different groups of cities and regions of Brazil.

The present study has numerous limitations. The use of different databases with different management routines can be considered a limitation. Another limitation was due to data unavailability and paucity, i.e., other variables shown to be related to TB could not be included, such as gender, alcohol consumption, drug abuse, diabetes prevalence, nutritional status, and supervised treatment. Regardless of these limitations, the analysis of risk variation in ecological studies, although considered simple for understanding social determinants in health conditions, is considered important in terms of generating new hypotheses, as in the case of the socioeconomic condition of the population groups, by explaining the health conditions of these groups.

Studies that seek to associate the occurrence of TB with socioeconomic indicators (representatives of living conditions) do not always find concordant results. Such divergence may be related to the level of territorial aggregation of the data, as well as the particular characteristics inherent in the populations under study. Although the correlation was negligible $(<0.30)$ in the majority of cities, it clearly demonstrated that a better educational level and higher income (as demonstrated by a higher HDI), as well as a lower level of inequality (as demonstrated for a lower GI), were associated with a lower incidence rate and mortality due to PTB. These results accord with the findings of Janssens (2008) and Dye (2009), which demonstrated an inverse relationship between TB incidence and increase in GDP, HDI, access to basic sanitation, and low infant mortality in 134 countries on five continents [7, 27]. Furthermore, Castañeda-Hernández et al. (2013) related HDI to TB incidence in 165 countries, and found higher TB rates in countries with lower HDI values [28]. A study in southern India confirmed a significantly higher prevalence of TB among people with a low standard of living index than among those with a medium or high standard of living [29]. An ecological study conducted in Porto Alegre (Brazil) indicated extremely high $\mathrm{TB}$ incidence rates in the poverty-stricken areas of cities, reinforcing the importance of inequality in income distribution in health determinants [15]. Results from Pelissari (2017) support a positive association between the TB incidence rate and income inequality distribution as well as an inverse association of this disease with mean per capita household income [30]. A study analyzing the overall 27 European Union member countries as well as Norway and Iceland using a public wealth index (which divides a nation's economic wealth by its level of social cohesion) and the inequality of income distribution ratio showed an inverse relationship between Proximity Warning Indicator (PWI) scores and TB rates [31]. In this context, it is important to note that the GI values in the different cities studied ranged from 0.47 to 0.53 , and according to the 2005 United Nations report, only Namibia (GI $=0.707$, $1993)$, Sierra Leone $(\mathrm{GI}=0.629,1989)$, Paraguay $(\mathrm{GI}=$ $0.578,2002)$, Chile $(\mathrm{GI}=0.571,2000)$, and Argentina $(\mathrm{GI}=0.522,2001)$ had a GI higher than Brazil.

At the ecological level, it was possible to verify that indicators related to income, schooling, and population density are associated with TB at the different levels of spatial aggregation [32]. Barr et al. associated a $10 \%$ increase in the proportion of families living below the poverty line with a $33 \%$ increase in the incidence of TB in neighborhoods in New York from 1984 to 1992 [33]. Magnati et al. found that a $1 \%$ increase in the proportion of households with more than one person per room represented a $12 \%$ increase in the average TB reporting rate for London districts between 1982 and 1991 [34]. Despite the relationship between TB and socioeconomic 
indicators, their association seems to be influenced by the spatial aggregation level of the data and by particular characteristics of the geographic areas under study.

Castañeda-Hernández et al. (2013) demonstrated that countries with an HDI of less than 0.60 had TB incidence rates above 250 cases/100,000 inhabitants and those with an HDI above 0.90 had a rate below 10 cases/ 100,000 inhabitants. Based on this information, a PTB incidence rate higher than 36 cases/100,000 inhabitants would be expected in a country with an HDI of 0.65 or 0.50, such as Brazil [28]. A recent study indicated that rates of cure, lost to follow-up, TB mortality, and resistance to TB drugs in Brazil remain far from the rates recommended by the WHO or have perhaps even deteriorated over the past 20 years [5]. However, during this same period, the TB incidence rate decreased. The deterioration of TB control rates (cure, lost to follow-up, TB drug resistance, mortality) and the negligible correlation between HDI and GI with the PTB incidence rate suggest the possibility of PTB under-reporting in Brazil.

The correlations between the social determinants studied (HDI and GI) and variables lost to follow-up and TB relapse were negligible, varying from a positive to negative correlation in different cities and regions and making difficult any definite inference about the association with these variables in this population. Possibly, these two variables are more related to the quality of healthcare services in each region than to social determinants of health in the general population.

Our findings did not confirm other studies conducted in Brazilian cities such as that by Oliveira (2000) in Campinas, which associated treatment lost to follow-up in illiterate or poorly educated subjects [35]. The study findings demonstrated a negative and positive correlation between death from TB and the HDI and GI, respectively, when analyzed as a national average. When we separated the cities into similar groups, the correlation with HDI became negative, demonstrating how heterogeneity can conceal differences. Similar data were found in countries with lower income inequality such as Norway [36]. In addition, the PTB mortality rate was higher than the national rate and higher than other studies conducted in Brazil in the group of larger cities [37]. A review article demonstrated that low-income and private areas in large cities in developed countries have the highest TB incidence and mortality rates [38]. Our findings are similar to those of two other studies that inversely associated TB mortality and HDI $[28,39,40]$. In a similar study, a direct association was found between TB mortality and the Robin Hood index (proportion of income that should be withdrawn from the rich and transferred to the poor to obtain an equitable distribution), average income ratio between the richest $10 \%$ and poorest $40 \%$, and the proportion of heads of household with average incomes between one and two minimum wages [40]. Note that poverty is a heterogeneous phenomenon that varies greatly in terms of type and magnitude between countries, regions, or neighborhoods. Socioeconomic and epidemiological indicators do not act in isolation, but according to their own conjuncture characteristics that should be considered in the analyses [41].

Concerning AIDS incidence, there is a higher concentration of cases in metropolitan areas in the Southeast macro-region (most populous region), and previous data demonstrated an unequal distribution of TB/HIV coinfection as well as isolated TB [42]. As in this study, in the United States, the HIV and AIDS epidemic is not evenly distributed across states and regions, but generally concentrated in urban areas. Higher rates of persons diagnosed with HIV or AIDS occur among those usually living in major metropolitan areas [43]. The incidence of AIDS has been shown to be more frequent in large cities, and data indicate a significant positive correlation with HDI and negative correlation with the GI. This finding suggests that in 2010, AIDS was more prevalent among persons with better social conditions, which may explain why Brazil had the lowest impact of AIDS on TB than other countries [42]. Some studies challenged the idea that poverty induces the HIV epidemic, demonstrating that HIV prevalence can be higher in wealthier populations $[44,45]$. However, it should be emphasized that in Brazil, only a small proportion of PTB patients are tested for HIV [46]. The epidemiological association of TB with AIDS represents a major challenge considering the difficulties in the organization of the control actions of the two diseases, which are performed by separate and disjointed control policies [47].

The GI is calculated from the Lorenz curve, which may underestimate the real value of the inequality if the richest group uses the income more efficiently than the poorest group. In this way, a GI value can have different meanings. Thus, while a GI of 0.50-such as for Brazilcould mean that $50 \%$ of the population has no income and the remaining $50 \%$ share the income equally, it could also mean that $75 \%$ of the population shares $25 \%$ of the income, and the remaining $25 \%$ shares $75 \%$ of the income [48]. Moreover, in this study, the AIDS incidence rate in the country was evaluated, not TB/AIDS coinfection rates. The databases (SINAN and DATASUS) are not unified and the HIV testing rate among TB cases in Brazil is very low. It is emphasized that data were only collected for patients diagnosed with AIDS, not for HIV-positive patients.

\section{Conclusion}

The correlation between the HDI and GI with the results of cure, relapse and loss of follow-up of the 
treatment varied greatly in the different groups of cities and regions of the country evaluated. We conclude that these variables may be more related to the quality of care provided by services than to social determinants in the general population. In addition, the decrease in the incidence of TBP followed by deterioration of TB control rates (cure, loss of follow-up, drug resistance, mortality) in the last 20 years and the negligible correlation of the HDI and GI with the incidence rate of PTB may suggest the possibility of PTB sub-notification in Brazil.

\begin{abstract}
Abbreviations
AIDS: Acquired Immune Deficiency Syndrome; CSDH: Commission on Social Determinants of Health; DATASUS: Department of the Unified Health System; GDP: Gross Domestic Product; GI: Gini Index; HDI: Human Development Index; HIV: Human Immunodeficiency Virus; IBGE: Brazilian Geographic and Statistics Institute; ICD: International Classification of Diseases; NTP: National Tuberculosis Control Program; PTB: Pulmonary Tuberculosis; SD: Standard Deviation; SIM: Mortality Information System; SINAN: Notifiable Diseases Information System; TB: Tuberculosis; UNDP: United Nations Program for Development; US: United States; WHO: World Health Organization
\end{abstract}

\section{Acknowledgements}

The authors acknowledge support for the research from the and the Graduate Programme in Medicine of the Federal University of Rio de Janeiro (UFRJ)

\section{Funding}

National Council for Scientific and Technological Development (CNPq).

\section{Availability of data and materials}

Data used for this study are public and can be accessed freely on electronic addresses of the Brazilian Government. We provided these electronic addresses on the text.

\section{Authors' contributions}

AZ participated in the study design and performed the data collection, statistical analysis, interpretation of results, and writing of the manuscript. RL participated in the study design, statistical analysis, interpretation of results, and writing of the manuscript. GW participated in the study design, interpretation of results, and writing of the manuscript. MBC oriented the study, participated in the study design, statistical analysis, interpretation of results, and writing of the manuscript. All authors read and approved the final version of the manuscript.

\section{Ethics approval and consent to participate}

The study was submitted to the Research Ethics Committee of the Federal University of Rio de Janeiro - Clementino Fraga Filho University Hospital (May 2013), which exempted the need for ethical approval because it is ecological research based on public secondary data.

\section{Consent for publication}

Not applicable.

\section{Competing interests}

The authors declare that they have no competing interests.

\section{Publisher's Note}

Springer Nature remains neutral with regard to jurisdictional claims in published maps and institutional affiliations.

\section{Author details}

${ }^{1}$ Instituto de Doenças do Tórax da Universidade Federal do Rio de Janeiro, Rio de Janeiro, RJ, Brazil. ${ }^{2}$ Instituto de Estudos em Saúde Coletiva da Universidade Federal do Rio de Janeiro, Rio de Janeiro, RJ, Brazil. ${ }^{3}$ Faculdade de Medicina de Petropolis/FASE, Petrópolis, RJ, Brazil. ${ }^{4}$ Hospital Universitário Clementino Fraga Filho, Cidade Universitária, Rua, Professor Rodolpho Paulo Rocco $n^{\circ} 255,6^{\circ}$ andar, Rio de Janeiro 21941-913, Brazil.
Received: 25 July 2018 Accepted: 26 April 2019

Published online: 08 May 2019

\section{References}

1. World Health Organization. Global tuberculosis report 2016. https://apps. who.int/iris/bitstream/handle/10665/250441/9789241565394-eng.pdf; jsessionid=CD0C3C8DDD8B75DDB853EF5C548C13BC?sequence=1. Accessed $21 \mathrm{Jul} 2017$.

2. Indicadores prioritários para o monitoramento do plano Nacional pelo fim da tuberculose como problema e saúde pública no Brasil.Bol Epidemiol 2017;48. http://portalarquivos2.saude.gov.br/images/pdf/2017/marco/23/ 2017-V-48-N-8-Indicadores-priorit--rios-para-o-monitoramento-do-PlanoNacional-pelo-Fim-da-Tuberculose-como-Problema-de-Sa--de-P--blica-noBrasil.pdf. Accessed 17 Aug 2018.

3. Incidência da Tuberculose no Brasil. Portal da Saúde. 2016. http://portalms. saude.gov.br/noticias/agencia-saude/22736-incidencia-da-tuberculose-cai20-2-no-brasil-em-uma-decada. Accessed 24 Aug 2018.

4. DATASUS. http://tabnet.datasus.gov.br/cgi/tabcgi.exe?ibge/cnv/pibmunbuf. def. Accessed 13 Oct 2016.

5. Ferreira AC, Rabahi M, Conde MB. Clinical treatment outcomes of tuberculosis treated with the basic regimen recommended by the Brazilian National Ministry of health using fixed-dose combination tablets in the greater metropolitan area of Goiânia. Brazil. J Bras Pneumol. 2013;39(1):76-83.

6. World Health Organization. Global Tuberculosis Report 2014. http://apps. who.int/iris/bitstream/10665/137094/1/9789241564809_eng.pdf. Accessed 2 Oct 2018.

7. Janssens JP, Rider $\mathrm{HL}$. An ecologic analysis of incidence of tuberculosis and per capita gross domestic product. Eur Respir J. 2008;32(5):1415-6.

8. Myers WP, Westenhouse JL, Flood J, Riley LW. An ecological study of tuberculosis transmission in California. Am J Public Health. 2006;96:685-90.

9. Ploubidis GB, Palmer MJ, Blackmore C, Lim TA, Manissero D, Sandgren A, Semenza JC. Social determinants of tuberculosis in Europe: a prospective ecological study. ERJ Express. 2012. https://doi.org/10.1183/09031936. 00184011

10. Barros RP, Foguel MN, Ulysses G. Desigualdade de renda no Brasil: uma análise da queda recente. Ipea. 2007;2:552.

11. Rasella D, Aquino R, Barreto ML. Impact of income inequality on life expectancy in a highly unequal developing country: the case of Brazil. J Epidemiol Community Health. 2013;67(8):661-6.

12. IBGE: Instituto Brasileiro de Geografia e Estatística. Censo Demográfico 2010: Características das populações e dos domicílios. http://seriesestatisticas.ibge. gov.br/. Accessed 17 Aug 2016

13. Vendramini SH, et al. Análise espacial da co-infecção tuberculose/HIV: relação com níveis socioeconômicos em município do sudeste do Brasil. Rev Soc Bras Med Trop. 2010;43(5):536-41.

14. Guimarães RM, Lobo AP, Siqueira EA, Borges TFF, Melo SCC. Tuberculosis, HIV, and poverty: temporal trends in Brazil, the Americas, and worldwide. J Bras Pneumol. 2012;38(4):511-7.

15. Acosta LMW, Bassanesi SL. The Porto Alegre paradox: social determinants and tuberculosis incidence. Rev Bras Epidemiol. 2014;17(2):88-101.

16. World Health Organization. Definitions and reporting framework for tuberculosis: 2013 revision, 2014. https://apps.who.int/iris/bitstream/handle/ 10665/79199/9789241505345_eng.pdf?sequence=1.

17. World Health Organization. Global tuberculosis control 2012. http://www. who.int/iris/bitstream/10665/75938/1/9789241564502_eng.pdf.

18. Casos confirmados notificados de tuberculose no Sistema de Informação de Agravos de Notificação (SINAN). Brasilia: Ministério da Saúde do Brasil; 2013. SINAN. http://tabnet.datasus.gov.br/cgi/tabcgi.exe?sinannet/cnv/tubercbr. def. Accessed 17 Oct 2016.

19. CID 10: Classificação Estatística Internacional de Doenças e Problemas Relacionados à Saúde - Décima Revisão. http://www.datasus.gov.br/cid10/ V2008/WebHelp/a15a19.htm. Accessed 17 Oct 2016.

20. United Nations. Human Development Report. 2016 United Nations development Programme. Income Gini Coefficient. http://hdr.undp.org/en/ content/income-gini-coefficient. Accessed 17 Nov 2016.

21. Characteristics of the indicators/qualification card: Gini index. 2016. http:// fichas.ripsa.org.br/2012/b-9/?l=pt_BR. Accessed 17 Nov 2017.

22. Commission on social determinants of health. A conceptual framework for action on the social determinants of health. http://www.who.int/social_ determinants/resources/csdh_framework_action_05_07.pdf. Accessed 16 Feb 2017. 
23. PNUD: Programa das Nações Unidas para o Desenvolvimento no Brasil - Índice de Desenvolvimento Humano Municipal, 2000 e 2010. http://www.br.undp. org/content/brazil/pt/home/idh0/rankings/idhm-municipios-2010.html. Accessed 16 Feb 2017.

24. Índice de Gini. Revista Desafios do Desenvolvimento. Brasília - DF; 2004. http://desafios.ipea.gov.br/index.php?option=com_content\&view= article\&id=2048:catid=28\&ltemid=23. Accessed 28 May 2017.

25. Veiga JE. Cidades imaginárias: o Brasil é menos urbano do que se calcula. Campinas: Autores Associados; 2002.

26. Hinkle DE, Wiersma W, Jurs SG. Applied statistics for the behavioral sciences. 5th ed. Boston: Houghton Mifflin; 2003.

27. Dye C, Lönnroth $\mathrm{K}$, Jaramillo E, Williams BG, Raviglione M. Trends in tuberculosis incidence and their determinants in 134 countries. Bull World Health Organ. 2009;87:683-91.

28. Castañeda-Hernández DM, Tobón-García D, Rodríguez-Morales AJ. Associación entre incidencia de tuberculosis e índice de desarrollo humano en 165 países del mundo. Rev Peru Med Exp Salud Publica. 2013;30(4):560-8.

29. Muniyandi M, Ramachandran R, Gopi PG, et al. The prevalence of tuberculosis in different economic strata: a community survey from South India. Int J Tuberc Lung Dis. 2007;9:1042-5.

30. Pelissari DM, Diaz-Quijano FA. Household crowding as a potential mediator of socioeconomic determinants of tuberculosis incidence in Brazil. PLoS One. 2017;12(4):e0176116. https://doi.org/10.1371/journal.pone.0176116 Accessed 18 Sept 2018.

31. Suk JE, Manissero D, Buscher G, Semenza JC. Wealth inequality and tuberculosis elimination in Europe. Emerg Infect Dis. 2009;15(11):1812-4.

32. San Pedro A, Oliveira RM. Tuberculose e indicadores socioeconômicos: revisão sistemática da literatura. Rev Panam Salud Publica. 2013;33(4):294-301.

33. Barr RG, Diez-Roux AV, Knirsch CA, Pablos-Mendez A. Neighborhood poverty and the resurgence of tuberculosis in new York City, 1984-1992. Am J Public Health. 2001;91(9):1487-93.

34. Mangtani P, Jolley DJ, Watson JM, Rodrigues LC. Socioeconomic deprivation and notification rates for tuberculosis in London during 1982-1991. BMJ. 1995;310(6985):963-6.

35. Oliveira HB, Moreira Filho DC. Abandono de tratamento e recidiva da tuberculose: aspectos de episódios prévios, Campinas, SP, Brasil, 1993-1994. Rev Saúde Pública. 2000;34(5):437-43.

36. Dahl E, Elstad JI, Hofoss D, Martin-Mollard M. For whom is income inequality most harmful? A multi-level analysis of income inequality and mortality in Norway. Soc Sci Med. 2006;63:2562-74.

37. Oliveira GP, Torrens AW, Bartholomay P, Barreira D. Tuberculosis in Brazil last ten years' analysis-2001-2010. Braz J Infect Dis. 2013;17(2):218-33.

38. Millet JP, Moreno A, Fina L, del Bano L, Orcau A, de Olalla PG, Cayla JA. Factors that influence current tuberculosis epidemiology. Eur Spine J. 2013;22(Suppl 4):539-48.

39. Munayco CV, Mújica OJ, León FX, del Granado M, Espinal MA. Social determinants and inequalities in tuberculosis incidence in Latin America and the Caribbean. Rev Panam Salud Publica. 2015;38(3):177-85.

40. Vicentin G, Santo AH, Carvalho MS. Mortalidade por tuberculose e indicadores sociais no município do Rio de Janeiro. Cien Saude Colet. 2002;7(2):253-63.

41. Barcellos C. Os indicadores da pobreza e a pobreza dos indicadores: Uma abordagem geográfica das desigualdades sociais em saúde. In: Barcellos $C$ editor. A geografia e o contexto dos problemas de saúde. Rio de Janeiro: Abrasco; 2008. p. 107-39.

42. Escombe AR, Moore DA, Gilman RH, Pan W, Navincopa M, Ticona E, et al. The infectiousness of tuberculosis patients coinfected with HIV. PLoS Med. 2008; 5(9):e188.

43. Center for Disease Control and Prevention - HIV/AIDS - Statistics Center. HIV and AIDS in the United States by geographic distribution. http://www.cdc.gov/hiv/ statistics/overview/geographicdistribution.html. Accessed 11 Mar 2018.

44. Kiersten J, Ann W. Risk factors for HIV infection in a national adult population: evidence from the 2003 Kenya demographic and health survey. J Acquired Immune Defic Synd. 2006;42:627-36.

45. Kongnyuy EJ, Wiysonge CS, Mbu RE, Nana P, Kouam L. Wealth and sexual behaviour among men in Cameroon. BMC Int Health Hum Rights. 2006;6:11.

46. Zenteno-Cuevas R, Montes-Villaseñor E, Morales-Romero J. Coronel-Martín del campo G, Cuevas B. coinfection and risk factors of tuberculosis in a Mexican HIV+ population. Rev Soc Bras Med Trop. 2011;44(3):282-5.

47. Guimarães RM, Lobo AP, Siqueira EA, Borges TFF, Melo SCC. Tuberculose, HIV e pobreza: tendência temporal no Brasil, Américas e Mundo. J Bras Pneumol. 2012:38(4):511-7.

48. Shorrocks AF. Ranking income distributions. Economica. 1983;50:3-17.

Ready to submit your research? Choose BMC and benefit from:

- fast, convenient online submission

- thorough peer review by experienced researchers in your field

- rapid publication on acceptance

- support for research data, including large and complex data types

- gold Open Access which fosters wider collaboration and increased citations

- maximum visibility for your research: over $100 \mathrm{M}$ website views per year

At $\mathrm{BMC}$, research is always in progress.

Learn more biomedcentral.com/submissions 